\title{
Editorial: Fundamental Characterization and Performance of Alternative Fuels
}

\author{
Tine Seljak ${ }^{1}$, Guillaume Vanhove ${ }^{2}$, Christine Mounaïm-Rousselle ${ }^{3}$, Véronique Dias ${ }^{4}$ and \\ Francesco Contino $^{4 *}$ \\ ${ }^{1}$ Faculty of Mechanical Engineering, University of Ljubljana, Ljubljana, Slovenia, ${ }^{2} P C 2 A$, Université de Lille, Lille, France, ${ }^{3}$ PRIMSE, \\ Université d'Orléans, Orléans, France, ${ }^{4}$ Department of Mechanical Engineering, Institute of Mechanics, Materials and Civil \\ Engineering, Université catholique de Louvain, Louvain-la-Neuve, Belgium
}

\section{Editorial on the Research Topic}

\section{Fundamental Characterization and Performance of Alternative Fuels}

\section{OPEN ACCESS}

Edited and reviewed by: Stephen Anthony Ciatti, Independent Researcher, Mount Vernon, WA, United States

*Correspondence: Francesco Contino francesco.contino@uclouvain.be

Specialty section: This article was submitted to Engine and Automotive Engineering, a section of the journal Frontiers in Mechanical Engineering

Received: 24 September 2020 Accepted: 25 September 2020 Published: 20 October 2020

Citation:

Seljak T, Vanhove G, MounaïmRousselle $C$, Dias $V$ and Contino $F$ (2020) Editorial: Fundamental Characterization and Performance of Alternative Fuels.

Front. Mech. Eng. 6:609504. doi: 10.3389/fmech.2020.609504
Conventional combustion has been exploited for power generation purposes since ancient times. Considering all relevant analyses of primary energy consumption, it is obvious that worldwide it will still play a major role in heat generation and will only slowly be replaced in generation of electricity. Despite unpreceded breakthroughs, growing capacity and large success of environmentally more acceptable technologies in terms of global warming potential as well as their growing share in the primary energy consumption, relevant analyses do not predict a significant midterm decrease of combustion-generated energy (International Energy Agency, 2019). In this view, the main scientific focus should be the development of clean combustion approaches which are, emission wise, on par or even supersede currently available renewable energy technologies.

In a uniform effort, supported by strong legislative framework research [RED (European Union, 2009) and RED II (European Union, 2018) in EU, American renewable energy and energy efficiency act (U.S. Congress, 2017) in United States, Renewable Energy Agency Regulation in Australia (Australian Renewable Energy Agency, 2016) and 5th strategic energy plan in Japan (Government of Japan, 2018)] groups across the globe already achieved giant leaps forward and recent years have brought about a wide pallet of new fuels, new combustion concepts and novel approaches which minimize the environmental footprint of combustion and hence target its most critical issues-emissions of $\mathrm{CO}_{2}$ and harmful pollutants together with sustainability in terms of resources required for production of fuels. The key steps for development of combustion are therefore well defined and firmly anchored in national and union development plans. Owing to these clear and implementable roadmap, new research needs are continuously arising from the everincreasing portfolio of fuels that are yet to be characterized and their position within the energy sector is yet to be established according to their performance in terms of $\mathrm{CO}_{2}$ and harmful emission reduction, as well as their implementability to novel combustion concepts.

With closely intertwined material and energy flows in a modern and circular economy, the impact of alternative fuels extends beyond the energy sector and is inherently linked to numerous other areas, calling for a holistic sector coupling comprising transportation, heat and power generation and energy storage, all supported by rigorous assessment of realistic environmental impact of new fuels and approaches for their production. To maximize the synergies, suitable alternative fuel candidates are continuously being mapped and integrated into novel combustion systems and their fundamental characterization is an integral part of the energy transition as it provides a knowledgebase required for large scale optimization and implementation of new technologies in the energy system of the future. 
Taking into account past, current and future needs in fundamental characterization of alternative fuels, the topics of this special issue aim at showcasing state-of-the-art research on novel fuels through contributions covering the fields of combustion science, mechanical engineering and lifecycle analysis, grasping a complete pallet of fuels that are emerging in the recent years. From bio-based alternatives for transportation fuels, over recycled carbon fuels linked to waste-management practices and synthetic fuels supporting the resilient and flexible energy system, the portfolio is extended also to biointermediates and bioliquids that serve as a low-cost and $\mathrm{CO}_{2}$ efficient alternative for heat and power generation.

The contributions in this special issue are addressing the key elements of each investigated fuel via holistic analyses, relying on numerical, analytical and experimental approach to deduct the most important phenomena, present in reciprocating internal combustion engines, gas turbines and atmospheric combustion devices.

With strong focus on transport applications, Dimitriadis et al. first comprehensively analyzed Hydrogenated Vegetable Oil through exhaust emissions in a standardized new European driving Cycle as a function of the injection and exhaust gas recirculation strategies, which highlights the potential of hydrogenated vegetable oil to reduce emissions, but exposed also the need to adapt engine operating strategies. The efforts to reduce the environmental footprint of transport were further extended by Boldaji et al. that with the aid of numerical investigations highlighted the impact of ethanol and gasoline surrogate and their behavior in low temperature combustion concepts. Costa et al. then intertwined the numerical and experimental analyses of dual fuel biodiesel and syngas combustion as well as n-butanol/n-heptane/air combustion in homogeneous charge compression ignition engine, which exposed how difficult it is still for computation fluid dynamics tools to appropriately predict the operational parameters of internal combustion engines using alternative fuels due to a lack of a structured experimental database.

The topical challenges of e-fuels in transport applications were tackled by Pochet et al. with comprehensive characterization of ammonia-hydrogen fueled homogeneous charge compression ignition engine, pinpoiting the presence of competing effect between ammonia-hydrogen mixture ratio and techno-economic feasibility, while also defining the future research needs in primary $\mathrm{NO}_{\mathrm{x}}$ reduction measures as well as $\mathrm{NO}_{\mathrm{x}}$ after treatment in ammonia combustion. The topic was further investigated by MounaïmRousselle and Brequigny that discussed the potential of ammonia

\section{REFERENCES}

Australian Renewable Energy Agency (2016). Australian Renewable Energy Agency Regulation 2016.

European Union (2009). Directive 2009/28/EC of the European Parliament and of the Council of 23 April 2009 on the promotion of the use of energy from renewable sources.

European Union (2018). Directive 2018/2001 of the European Parliament and of the Council of 11 December 2018 on the promotion of the use of energy from renewable sources.

Government of Japan (2018). 5th Strategic Energy Plan 2018.

International Energy Agency (2019). World Energy Outlook 2019. Paris, France: OECD. as a fuel for spark ignition engines, revealing that compression ratio of 10:1 may be sufficient to obtain stable combustion of ammonia with $5-10 \%$ of $\mathrm{H}_{2}$ addition or even without $\mathrm{H}_{2}$. To put in light different alternative fuels, Dias et al. then evaluated the energy and economic costs of production, storage and distribution of various e-fuels, including hydrogen, ammonia, methane, and methanol with the aim to provide a comprehensive comparative analysis in the frame of energy transition.

As energy transition will strongly be supported also by renewable bio-based and waste-based resources, Shu et al. focused particularly on utilization of liquefied natural gas and liquefied biogas and their mixtures containing C1-C5 alkanes in order to understand the role of bio-based alternative in combustion and knocking propensity. As one of the main pillars of defossilization in heating, cooling and power generation, bio-based resources were then further evaluated also by Rosec et al. that provided the first comparative analysis of different bio-intermediates and waste-derived fuels from established processes in the wood industry, biodiesel production and nanocellulose production. The analysis revealed highly beneficial impact of specific alternative fuel properties on reduction of harmful emissions as well as $\mathrm{CO}_{2}$, which are implementable in various power generation units, thus extending the focus of special issue also to stability and security of energy supply throughout the industry.

Within these contributions, the investigations are once again confirming the necessity for even deeper research into fundamentals of alternative fuels in order to fully understand the underlying phenomena on production, storage and utilization which enables the alternative fuels to outperform their fossilderived counterparts on several levels. At the same time, the current knowledgebase, extended with the featured special issue is already providing fully feasible pathways that enable imminent utilization and exploitation of alternative fuels in efficient and clean way, making its own mark in the energy transition that will in the mid-term strongly rely on a featured approaches toward improvements in combustion science.

\section{AUTHOR CONTRIBUTIONS}

All authors listed have made a substantial, direct, and intellectual contribution to the work and approved it for publication.

U.S. Congress (2017). American Renewable Energy and Efficiency Act H.R.2746, 115th Congress (2017-2018).

Conflict of Interest: The authors declare that the research was conducted in the absence of any commercial or financial relationships that could be construed as a potential conflict of interest.

Copyright (C) 2020 Seljak, Vanhove, Mounaïm-Rousselle, Dias and Contino. This is an open-access article distributed under the terms of the Creative Commons Attribution License (CC BY). The use, distribution or reproduction in other forums is permitted, provided the original author(s) and the copyright owner(s) are credited and that the original publication in this journal is cited, in accordance with accepted academic practice. No use, distribution or reproduction is permitted which does not comply with these terms. 